\title{
Venous Thromboembolism Rates in Transferred Patients: A Cross-Sectional Study
}

\author{
Samuel Lai, MD' , Eric Ton, MD, MBA ${ }^{2}$, Marianne Lovejoy, RN, BSN ${ }^{7}$, William Graham, $M D^{3}$, \\ and Alpesh Amin, MD, MBA \\ 'University of California, Irvine Medical Center, Orange, CA, USA; ${ }^{2}$ Kaiser Sunset Medical Center, Los Angeles, CA, USA; ${ }^{3}$ Cedars Sinai Medical \\ Center, Los Angeles, CA, USA.
}

BACKGROUND: Patients undergoing a transfer during a hospitalization may be more likely to be diagnosed with a venous thromboembolism (VTE) than patients who are not transferred.

OBJECTIVE: To determine whether transferred patients have an increased prevalence of VTE diagnosis.

DESIGN: This was a cross-sectional study comparing VTE diagnosis rates between transferred patients and non-transferred patients. For the years 2012-2014, the University HealthSystem Consortium database of multiple community and academic medical centers throughout the United States was parsed using ICD-9 VTE diagnosis codes and patient's point of origin.

PATIENTS: Patients were included in the analysis as transferred patients if their point of origin was a skilled nursing facility, another acute care facility or another facility. Nontransferred patients were those whose point of origin was a clinic or those with a non-facility point of origin.

MAIN MEASURES: The primary comparison of VTE prevalence during hospitalization between transferred and non-transferred patients in the years 2012-2014. Subgroup analysis looked at level I trauma status and case mix index (CMI) to determine whether these had an effect on VTE prevalence.

KEY RESULTS: From 2012 to 2014, a total of 225 unique hospitals and 12,036,029 patients were analyzed, and the prevalence of VTE in transferred patients and nontransferred patients was $3.43 \%$ and $1.91 \%$ (RR 1.80; 95\% CI $1.78-1.81 ; P<0.001)$, respectively. VTE prevalence in transferred versus non-transferred patients at level I trauma centers was $3.42 \%$ versus $1.88 \%(\mathrm{RR}=1.82 ; 95 \%$ CI 1.80 $1.85 ; P<0.001)$. The 3 -year average CMI of transferred versus non-transferred patients was 3.53 versus $2.26(P<0.001)$. CONCLUSIONS: Transferred patients have a higher prevalence of VTE than non-transferred patients, regardless of level I trauma designation. Higher VTE rates in transferred versus non-transferred patients was minimally correlated with $\mathrm{CMI}$.

KEY WORDS: quality assessment; quality improvement; public health. J Gen Intern Med 33(1):42-9

DOI: $10.1007 / \mathrm{s} 11606-017-4166-Z$

(C) Society of General Internal Medicine 2017

Received January 12, 2017

Revised June 26, 2017

Accepted August 11, 2017

Published online September 15, 2017

\section{INTRODUCTION}

Venous thromboembolism (VTE), which includes pulmonary embolism (PE) and deep vein thrombosis (DVT), is an increasing cause of morbidity, mortality and economic burden in the United States, ${ }^{1}$ with $60,000-300,000$ deaths per year in the United States attributed to VTE. ${ }^{2-4}$ Many risk factors for VTE have been studied, including a multitude of inherited and acquired traits. Hospitalization is a risk factor that likely reflects a patient's immobilization and illness severity. ${ }^{5}$ Among hospitalized patients, transferred patients have been shown to have higher rates of mortality, likely due to their higher levels of acuity and severity of illness. ${ }^{6,7}$ In our institution, the University of California, Irvine Medical Center, we have observed a trend of increasing rates of VTE in patients transferred from outside hospitals. Indeed, a retrospective analysis over a 1-year period showed significantly increased rates of VTE in both surgical and non-surgical patients who had been transferred from an outside hospital. ${ }^{8}$

The purpose of this study is thus to determine whether the increased incidence of VTE in patients transferred during hospitalization is unique to our institution, or whether this is a national trend. We hypothesize that, similar to the results observed in our internal investigation, transferred patients will have a higher prevalence of VTE than non-transferred patients on a national scale.

\section{METHODS}

\section{Cross-Sectional Study}

Data were obtained from the University HealthSystem Consortium (UHC) Clinical Database (CDB), which pools data from more than $95 \%$ of the non-profit academic medical centers and affiliated teaching and specialty hospitals in the United States. The CDB allows for rapid search and retrieval of healthrelated metrics from all member hospitals at a population level.

\section{Study Population}

The CDB allows for categorization of patients based on multiple criteria but we focused on admission source, VTE ICD-9 coding, age, length of stay and years of interest. We applied these criteria to two groups of patients, one of which we 
labeled "non-transferred patients" and the other "transferred patients." Admission source criteria for non-transferred patients were "clinical referral" or "non-facility point of origin," with the latter including patients admitted from home or an out-of-system clinic. For transferred patients, admission source criteria were defined as "transfer from a different hospital," "transfer from another facility," or "transfer from skilled nursing facility." "Another facility" is defined here as patients arriving from long-term acute care, acute rehab units or inpatient psychiatry facilities.

Utilizing these criteria, we were able to identify patients who at any point during their hospitalization were transferred to another hospital. Both transferred and non-transferred patients were then queried for ICD-9 codes for VTE (see Appendix A), and the criteria were narrowed to those between the ages of 18 and 100 years and a length of stay of 0 to 120 days.

Then, given the paucity of data in the database before 2012, we chose to look at the years 2012-2014. This analysis yielded 225 unique hospitals and 12,036,029 patients, among which $1,445,786$ met the aforementioned definition of "transferred," with the remaining 10,593,734 classified as "non-transferred" (see Appendix Table 3).

\section{Study Measures}

The primary analysis compared the prevalence of VTE between transferred and non-transferred patients. Secondary analyses examined the differences in prevalence between transferred and non-transferred patient groups stratified by (1) level I trauma center status and (2) patient case mix index (CMI). We chose level I trauma center status because of our hypothesis that transferred patients would be likely to have a longer duration of immobility and higher illness severity. Level I trauma centers generally have a higher average rate of transfers, given their nature as the highest-accepting resource for health facilities in nearby regions. ${ }^{9,10}$

We utilized the CMI as a surrogate tool to estimate severity of illness and disease complexity for transferred and non-transferred patient groups. We hypothesized that the higher rate of VTE diagnosis in our transferred patient population was due, in part, to greater disease complexity and illness severity. The CMI is calculated by averaging the Medicare Severity Diagnosis Related Groups (MS-DRG) weight of the selected patients discharged within the period of interest. ${ }^{11}$ The data were further stratified into six CMI segments within level I trauma centers and non-level I trauma centers, for a total of 12 groups for each year.

We compared the proportion of patients with VTE in the transferred and non-transferred groups using a chi-square test. The ratio of these proportions was calculated and a 95\% confidence interval surrounding this relative risk was generated assuming a normal distribution. This was repeated with stratification for trauma center status and for the sextile of the CMI. Calculations were completed using Microsoft Excel ${ }^{\circledR}$ 2016 (version 1609).

\section{RESULTS}

\section{Primary Analysis}

While the total prevalence averaged $2.09 \%$ over 3 years, the prevalence of VTE was $3.43 \%$ in transferred patients versus $1.91 \%$ in non-transferred patients (RR 1.80 ; 95\% CI 1.78 $1.81 ; P=<0.001$ ). (Table 1). Overall, transferred patients accounted for approximately $10-13 \%$ of total hospitalized patients and were associated with roughly $20 \%$ of all VTE in each of the 3 years studied (See Appendix Tables 3 and 4).

\section{Level I Trauma Center Subgroup Analysis}

From 2012 to 2014, patients transferred to level I trauma centers averaged $13.4 \%$ of total admissions, whereas transfers accounted for an average of $10.6 \%$ of total admissions at nonlevel I trauma centers. VTE prevalence in transferred versus non-transferred patients at level I trauma centers was $3.42 \%$ versus $1.88 \%(\mathrm{RR}=1.82 ; 95 \% \mathrm{CI}, 1.80-1.85 ; P<.001)$. The respective VTE prevalence rates were $3.43 \%$ and $1.94 \%$ $(\mathrm{RR}=1.77 ; 95 \% \mathrm{CI}, 1.74-1.79 ; P<.001)$ at non-level $\mathrm{I}$ trauma centers (Table 2).

\section{Case Mix Index Subgroup Analysis}

The increased rate for VTE in transferred patients remained statistically significant when all selected hospitals were stratified by CMI, with the exception of the bottom sextile in 2014 (Fig. 1). At level I trauma centers, there was a statistically significant increase in the rate of VTE in transferred patients at all levels of CMI (Fig. 2). Non-level I trauma centers in the bottom sextile of CMI had no increase in VTE rate in transferred patients for years included in the search (Fig. 3).

Lastly, the CMI in transferred versus non-transferred patients with VTE for the total 3-year period was 3.53 versus 2.26, which was statistically significant $(p<0.001$; see Appendix Table 6).

\section{DISCUSSION}

To our knowledge, this is the first study analyzing a patient's transfer status and its relation to VTE prevalence. Based on the above results from 3 different years and in different types of hospitals throughout the United States, this cross-sectional study reveals a higher prevalence of VTE in transferred patients. In our secondary analyses comparing transferred and non-transferred patients, we found a very small statistical difference in VTE rates between level I trauma and non-level I trauma centers. This extremely small difference implies that level I trauma status is not significantly associated with VTE prevalence. Lastly, as CMI increases from the sixth to first sextile, there is a statistically significant correlation with the relative risk of VTE in both transferred and non-transferred patients during the years 2013-2014, which likely reflects the increased acuity and illness severity of transferred patients. 
Table 1 Yearly VTE Prevalence in Transferred vs. Non-transferred Patients

\begin{tabular}{|c|c|c|c|c|c|c|}
\hline & \multicolumn{2}{|c|}{ Transferred patients } & \multicolumn{4}{|c|}{ Non-transferred patients } \\
\hline & Number & Prevalence & Number & Prevalence & Relative risk (RR) & $P$-value \\
\hline 2014 & 495,125 & $3.49 \%$ & $3,706,285$ & $1.94 \%$ & 1.80 & $<0.001$ \\
\hline 2013 & 490,778 & $3.37 \%$ & $3,576,591$ & $1.90 \%$ & 1.78 & $<0.001$ \\
\hline 2012 & 459,856 & $3.41 \%$ & $3,307,394$ & $1.88 \%$ & 1.81 & $<0.001$ \\
\hline
\end{tabular}

The higher rate of VTE in transferred patients is likely due to increased immobilization and illness severity. As described by Clough et al., transferred patients generally have higher rates of morbidity or mortality, regardless of the reason for their transfer, due to increased illness severity. ${ }^{6}$ Our secondary analyses of CMI supports this idea by describing a statistically significant difference between the CMI of transferred and nontransferred patients over the period 2012-2014 (Appendix Tables 5 and 6 and Figs. 2, 3, 4, 5 and 6). In addition, these patients also likely have higher rates of immobility. As Golestanian et al. and Rosenberg et al. have shown, transferred patients have longer lengths of stay, which likely contributes to higher rates of immobility and VTE incidence. ${ }^{10,12}$

As shown in Table 2, level I trauma status had a very small, statistically significant effect on VTE prevalence when comparing transferred versus non-transferred patients. One possible explanation for the very small difference is that all hospitals have comparable adherence to VTE prevention guidelines. A wide range of studies have shown that hospital utilization of VTE prevention protocols and adherence to society guidelines is suboptimal. In 2007, Amin et al. showed that among all acute medical inpatients considered at high risk for VTE prophylaxis, as defined by the sixth edition of the American College of Chest Physicians (ACCP) guidelines for VTE prevention, only $40 \%$ received adequate prophylaxis. ${ }^{13}$ Similarly, the VTE START [venous thromboembolism study to assess the rate of thromboprophylaxis], conducted by Amin et al. in 2010 to assess the adequacy of the type, duration and dose of VTE prophylaxis, revealed low adherence levels of $12.7 \%$ and $16.4 \%$ for medical and surgical patients, respectively. ${ }^{14}$

Importantly, our data show that transferred patients accounted for a disproportionate share of VTE during the study period. Transferred patients constituted $12.0 \%$ of total hospitalized patients, yet accounted for $19.9 \%$ of VTE diagnoses. This raises three concerns that can be extrapolated from our data into the broader range of health care policy: 1) If a VTE is diagnosed as a hospital-acquired condition, then which hospital should incur the VTE diagnosis penalty, the transferring or accepting hospital? 2) How can transferring hospitals be encouraged to improve guideline adherence? 3) Should there be special VTE screening protocols for transferred patients?

The Centers for Medicare \& Medicaid Services (CMS) and The Joint Commission have developed performance measures that affect Medicare reimbursement. As an example, Patient Safety Indicator \#12 (PSI-12) assesses perioperative VTE rates via ICD coding. ${ }^{15}$ In addition, since 2007 , CMS has required that discharge diagnoses be labeled as "present on admission" or "not present on admission" in order to accurately determine penalties and payments. ${ }^{16,17}$ Those noted to be in the lowest quartile of quality measures will see a reduction in Medicare reimbursements. In order for a condition to be qualified as present on admission, the accepting center physician must document either that they suspect that it is present, that the condition is pre-existing, or that the patient underwent treatment for the condition. ${ }^{18}$ However, as reported by Usher et al., a common problem in handoffs between hospitals is that the documentation in the transfer packet sent to the accepting hospital is incomplete. ${ }^{19}$ A large systematic review by Ong et al. in 2011 also showed a significant breakdown in communication between transferring and accepting hospitals, leading to poor patient outcomes. ${ }^{20}$ With documentation frequently incomplete on arrival, accurate coding of present-on-admission conditions is difficult. Additional research on inter-hospital communication could greatly improve diagnosis, treatment and precise reporting to Medicare of preventable hospital conditions.

Since transferred patients have a higher rate of VTE diagnosis, there may be some benefit in screening tests to increase early VTE detection and prevention of PE or mortality. Screening venous duplex ultrasound has been studied in other high-risk populations, such as high-risk trauma or orthopedic surgery patients. For example, in 2016, Casey et al. showed that screening high-risk trauma patients for VTE with venous duplex ultrasound reduced their risk of PE, which the authors hypothesized was due to earlier detection and treatment of asymptomatic DVT. However, the ACCP guidelines recommend against screening ultrasound for DVT in all but a very select group of high-risk trauma patients with suboptimal or no thromboprophylaxis. ${ }^{21}$ The results of this study suggest that perhaps there is a subset of transferred patients that

Table 2 Subgroup: VTE Prevalence Rates in Level I and Non-Level I Trauma Centers for 2012-2014

\begin{tabular}{lllllll}
\hline \hline & \multicolumn{2}{l}{$\begin{array}{l}\text { VTE prevalence in } \\
\text { transferred patients }\end{array}$} & \multicolumn{2}{l}{$\begin{array}{l}\text { VTE prevalence in non- } \\
\text { transferred patients }\end{array}$} \\
\hline & Number & Prevalence & Number & Prevalence & Relative risk (RR) & $P$-value \\
Level I trauma & 28,602 & $3.42 \%$ & 101,730 & $1.88 \%$ & 1.82 & $<0.001$ \\
Non-level I trauma & 20,919 & $3.43 \%$ & 100,504 & $1.94 \%$ & 1.77 & $<0.001$ \\
\hline
\end{tabular}



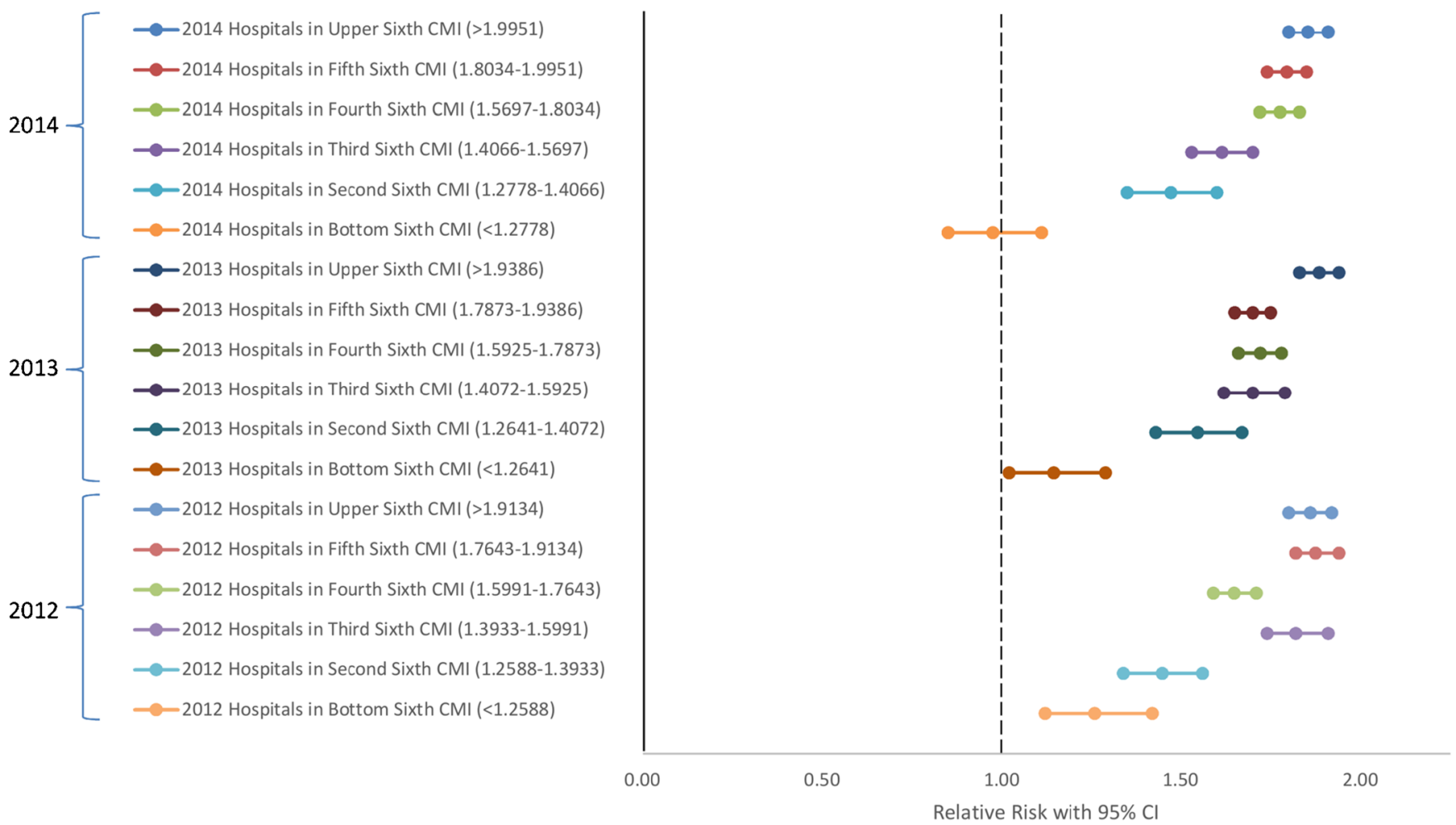

Figure 1 Relative risk of VTE in transferred versus non-transferred patients by CMI grouping.

would benefit from some type of screening. Further research is needed to provide a cost-benefit analysis of such screening methods. In addition to the uncertainty regarding the optimal screening mechanisms and patient population, hospitals are penalized for diagnosing hospital-acquired conditions. In a 2013 study, Bilimoria et al. reported that increased screening of patients to ensure compliance with Medicare quality measures was associated with a rise in the rates of reported VTE. ${ }^{22}$ If increased compliance with Medicare quality measures is going to continue to be linked to reimbursement, policy discussions are needed to determine the need for screening and its interplay with penalties.

Lastly, as discussed above, adherence to VTE prevention guidelines is subpar in many hospitals. If reimbursement rates and Medicare penalties are associated in part with VTE prevention, then further steps need to be taken to improve compliance. There are various methods known to improve adherence. For example, in 2014, Khoury et al. demonstrated 99\% adherence to VTE prophylaxis through the use of a computer-based clinical decision-making system. ${ }^{23}$ However, the failure of physicians to appreciate the benefits of recommended therapy and the lack of adequate physician education about such guidelines ${ }^{24,25}$ may contribute to the continued low rates of adherence. Regardless of the reason, stronger policies, procedures and incentives are needed in order to improve hospital adherence to prevention guidelines and to reduce the downstream effects of non-adherence.

\section{LIMITATIONS}

Our study has some limitations: (1) the UHC is a data-driven tool that depends on accurate coding; (2) data are obtained at a population level and not an individual level; (3) it is not possible to control for other known VTE risk factors.

As the CDB primarily comprises administrative billing data for coded patients, coding errors may have resulted in the inappropriate inclusion or exclusion of patients, although these errors likely affected both transferred and non-transferred patients equally. In addition, because information was gathered from a multi-hospital national database, individual-level data could not be obtained, and thus regression analyses could not be performed. Population-level statistics is the only tool at the UHC's disposal; however, this was adequate for the purposes of our study. As future studies are implemented, individual-level data can be gathered to assess and control for known VTE risk factors.

\section{CONCLUSION}

To the best of our knowledge, this is the first study to investigate whether transfer status is associated with VTE diagnosis. Our study shows that the rate of VTE diagnosis is higher in transferred patients than non-transferred patients across all types of hospitals in the United States.

Corresponding Author: Alpesh Amin, MD, MBA; University of California, Irvine Medical Center, Orange, CA, USA (e-mail: ANAmin@uci.edu). 


\section{Compliance with Ethical Standards:}

Conflict of Interest: The authors declare that they have no conflict of interest.

\section{REFERENCES}

1. Grosse SD, Nelson RE, Nyarko KA, et al. The economic burden of incident venous thromboembolism in the United States: A review of estimated attributable healthcare costs. Thromb Res. 2016;137:3-10.

2. Heit JA. The epidemiology of venous thromboembolism in the community. Arterioscler Thromb Vasc Biol. 2008;28(3):370-372.

3. Leavitt M. Message from the Secretary, U.S. Department of Health and Human Services. In: Office of the Surgeon General (US); National Heart, Lung, and Blood Institute (US). The Surgeon General's Call to Action to Prevent Deep Vein Thrombosis and Pulmonary Embolism. Office of the Surgeon General (US); 2008.

4. The Lancet Haematology. Thromboembolism: an under appreciated cause of death. The Lancet Haematology. 2015;2(10):e393.

5. Clough JD, Kay R, Gombeski WR Jr, et al. Mortality of patients transferred to a tertiary care hospital. Cleve Clin J Med. 1993;60(6):449-54.

6. Gordon H, Rosenthal, G. Impact of Interhospital Transfers on Outcomes in an Academic Medical Center: Implications for Profiling Hospital Quality. Medical Care. 1996;34(4):295-309.

7. Eveillard M, Quenon J, Rufat $\mathbf{P}$, et al. Association Between Hospital Acquired Infections and Patients' Transfers. Infect Control Hosp Epidemiol. 2001;22(11):693-696.

8. Graham WB, Ton E, Amin A, et al. Venous Thromboembolisms on Arrival: An Analysis of Transfers to UC Irvine Medical Center. Poster. Presented at the 17th Annual SHM Meeting; September 2015; Washington, DC.

9. Golestanian E, Scruggs JE, Gangnon RE, et al. Effect of interhospital transfer on resource utilization and outcomes at a tertiary care referral center. Crit Care Med. 2007;35(6):1470-1476.

10. Durairaj L, Will JG, Torner JC, et al. Prognostic factors for mortality following interhospital transfers to the medical intensive care unit of a tertiary referral center. Crit Care Med. 2003;31(7):1981-1986.

11. Definition of Case Mix for Hospitals. Available at: http://www. healthandhospitalcommission.com/ docs/May26Meeting/ CasemixIndexDefintion.pdf. Accessed April 2, 2017.

12. Rosenberg A, Hofer T, Strachan C, et al. Accepting Critically Ill Transfer Patients: Adverse Effects on a Referral Center's Outcome and Benchmark Measures. Ann Intern Med. 2003;138:882-890.

13. Amin A, Stemkowski S, Lin $\mathbf{J}$, et al. Thromboprophylaxis rates in US medical centers: success or failure? J Thromb Haemost. 2007;5(8):1610-1616.

14. Amin A, Spyropoulos AC, Dobesh P, et al. Are hospitals delivering appropriate VTE prevention? The venous thromboembolism study to assess the rate of thromboprophylaxis (VTE START). J Thromb Thrombolysis. 2010;29(3):326-339.

15. PSI \# 12 Postoperative Pulmonary Embolism or Deep Vein Thrombosis. Agency for Healthcare Research and Quality. Available at: http://www. qualityindicators.ahrq.gov/Downloads/Modules/PSI/V41/TechSpecs/ PSI\%2012\%20Postoperative\%20Pulmonary\%20Embolism\%20or\%20 Deep\%20Vein\%20Thrombosis.pdf. Accessed April 2, 2017.

16. Khanna R, Kim S, Jenkins I, et al. Predictive Value of the Present-OnAdmission Indicator for Hospital-Acquired Venous Thromboembolism. Medical Care. 2015;53(4):e31-e36.

17. Cohen AT, Alikhan R, Arcelus JI, et al. Assessment of venous thromboembolism risk and the benefits of thromboprophylaxis in medical patients. Thromb Haemost. 2005;94:750-759.

18. Cafardi SG. Accuracy of Coding in the Hospital-Acquired ConditionsPresent on Admission Program, Final Report. 2012. Appendix B.

19. Usher MG, Fanning C, Wu D, et al. Information handoff and outcomes of critically ill patients transferred between hospitals. J Crit Care. 2016;36:240-245.

20. Ong MS, Coiera E. A systematic review of failures in handoff communication during intrahospital transfers. Jt Comm J Qual Patient Saf. 2011;37(6):274-284.

21. Geerts WH, Berggvist D, Pineo GF, et al. Prevention of venous thromboembolism: American College of Chest Physicians evidence-based clinical practice guidelines (8th edition). Chest. 2008;133(6 Suppl):381S-453S.

22. Billimoria $\mathbf{K Y}$, Chung $\mathbf{J}$, Ju $\mathbf{M H}$, et al. Evaluation of surveillance bias and the validity of the Venous Thromboembolism quality measure. JAMA. 2013;310(14):1482-1489.
23. Khoury L, Dangodara AA, Lee JA, et al. Implementation of a Mandated Venous Thromboembolism Clinical Order Set Improves Venous Thromboembolism Core Measures. Hosp Pract. 2014;42(5):89-99.

24. Piechowski KL, Elder S, Efird LE. Prescriber knowledge and attitudes regarding non-administration of prescribed pharmacological venous thromboembolism prophylaxis. J Thromb Thromboly. 2016;42(4):463-470.

25. Cabana MD, Rand CS, Powe NR, et al. Why don't physicians follow clinical practice guidelines? A framework for improvement. JAMA. 1999;282(15):1458-65

\section{APPENDIX A}

\section{VTE Diagnosis Codes from ICD-9}

\author{
a. $415.11,415.13,415.19,451.11,451.19,451.2,451.81$, \\ $451.9,453.2,453.40,453.41,453.87,453.89,453.9$
}

\section{APPENDIX B}

Table 3 Study Population: Transferred patients, Non-Transferred Patients, and All Patients from 2012 to 2014

\begin{tabular}{lllll}
\hline Year & $\begin{array}{l}\text { Transferred } \\
\text { patients } \\
\text { across all } \\
\text { hospitals }\end{array}$ & $\begin{array}{l}\text { Non- } \\
\text { transferred } \\
\text { patients } \\
\text { across all } \\
\text { hospitals }\end{array}$ & $\begin{array}{l}\text { Total } \\
\text { number of } \\
\text { patients } \\
\text { across all } \\
\text { hospitals }\end{array}$ & $\begin{array}{l}\text { \% of } \\
\text { transferred } \\
\text { patients }\end{array}$ \\
\hline 2012 & 459,856 & $3,307,394$ & $3,767,250$ & $12.21 \%$ \\
2013 & 490,778 & $3,508,618$ & $4,067,369$ & $13.72 \%$ \\
2014 & 495,125 & $3,634,329$ & $4,201,410$ & $11.78 \%$ \\
Totals & $1,445,759$ & $10,590,270$ & $12,036,029$ & $12.01 \%$ \\
\hline
\end{tabular}

\section{APPENDIX C}

Table 4 Study Population: VTE Rates in Transferred, NonTransferred and All Patients from 2012 to 2014

\begin{tabular}{lllll}
\hline \hline Year & $\begin{array}{l}\text { VTE rates } \\
\text { transferred } \\
\text { patients } \\
\text { across all } \\
\text { hospitals }\end{array}$ & $\begin{array}{l}\text { VTE rates } \\
\text { non- } \\
\text { transferred } \\
\text { patients } \\
\text { across all } \\
\text { hospitals }\end{array}$ & $\begin{array}{l}\text { VTE } \\
\text { rates } \\
\text { total } \\
\text { number } \\
\text { of } \\
\text { patients } \\
\text { across all } \\
\text { hospitals }\end{array}$ & $\begin{array}{l}\text { \% of VTE } \\
\text { from } \\
\text { transferred } \\
\text { patients }\end{array}$ \\
& & & 77,970 & \\
\hline 2012 & 15,665 & 62,305 & 84,532 & $19.59 \%$ \\
2013 & 16,559 & 67,973 & 89,883 & $19.94 \%$ \\
2014 & 17,927 & 71,956 & 251,385 & $19.87 \%$ \\
Totals & 50,151 & 202,234 & & \\
\hline
\end{tabular}




\section{APPENDIX D}

Table 5 Pearson's Correlation Coefficient and $\boldsymbol{P}$-Value for CMI in All Hospitals from 2012 to 2014

\begin{tabular}{lll}
\hline \hline CMI year & Correlation coefficient $\boldsymbol{r}$ & $\boldsymbol{P}$-value \\
\hline 2012 & 0.028 & 0.69 \\
2013 & 0.347 & $<0.001$ \\
2014 & 0.290 & $<0.001$ \\
\hline
\end{tabular}

Pearson's correlation coefficient $\mathrm{r}$ quantifies the degree of correlation between two values. In this case, we looked at increasing CMI in relation to increasing VTE relative risk. As shown above, the values for 2013 and 2014 show statistically significant correlations. By statistical convention, the values of 0.347 and 0.290 for the years 2013 and 2014, respectively, are considered a "weakly positive linear relationship."

Below are the graphical representations by CMI year:

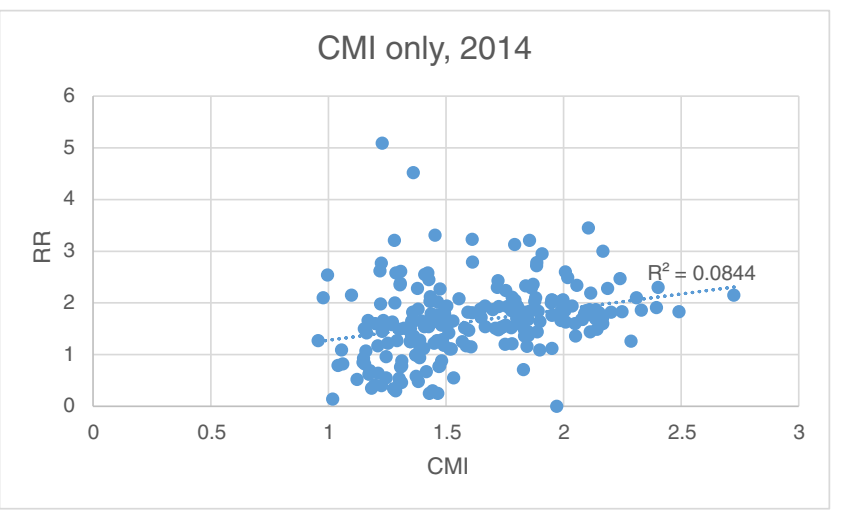

Figure 2 Correlation Between Case Mix Index and VTE Relative Risk for 2014

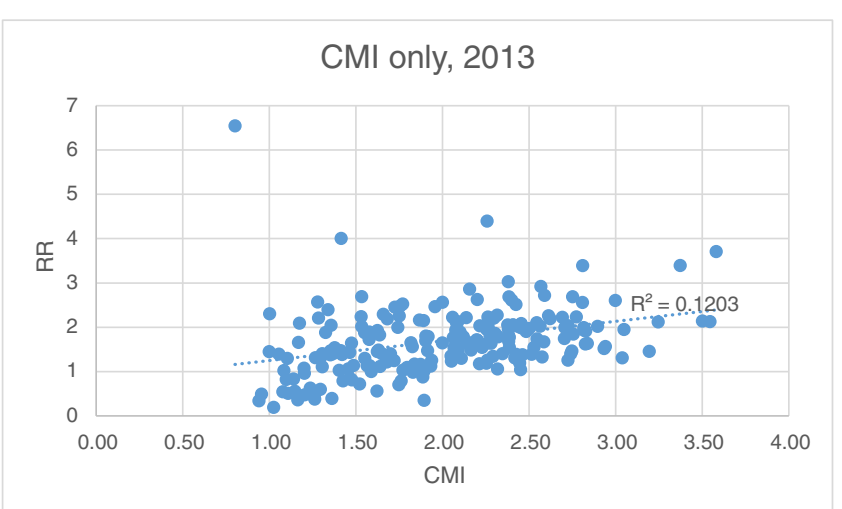

Figure 3 Correlation Between Case Mix Index and VTE Relative Risk for 2013

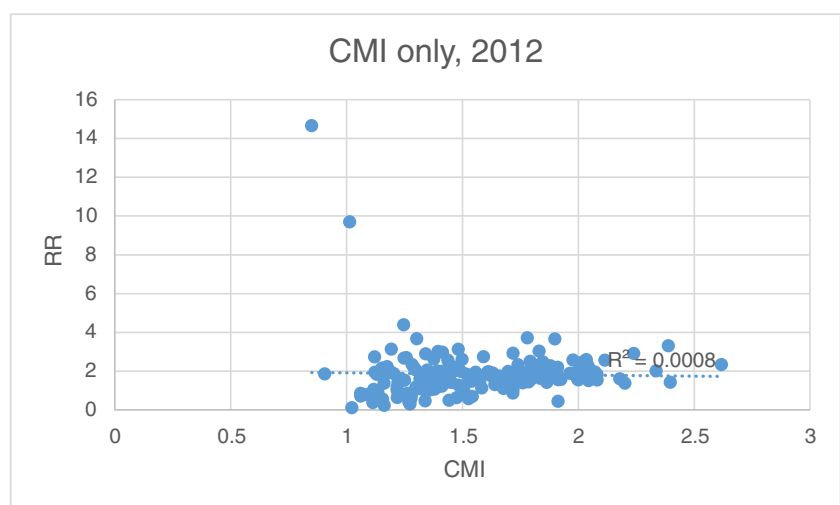

Figure 4 Correlation Between Case Mix Index and VTE Relative Risk for 2012

\section{APPENDIX E}

Table 6 CMI for Transferred Patients with VTE vs. NonTransferred Patients with VTE from 2012 to 2014

\begin{tabular}{llll}
\hline \hline Year & $\begin{array}{l}\text { CMI transferred } \\
\text { patients with VTE }\end{array}$ & $\begin{array}{l}\text { CMI non-transferred } \\
\text { patients with VTE }\end{array}$ & $\begin{array}{l}\boldsymbol{P} \text { - } \\
\text { value }\end{array}$ \\
\hline 2012 & 3.49 & 2.46 & $<0.001$ \\
2013 & 3.52 & 2.44 & $<0.001$ \\
2014 & 3.57 & 2.43 & $<0.001$ \\
Totals & 3.53 & 2.45 & $<0.001$ \\
\hline
\end{tabular}




\section{APPENDIX F}

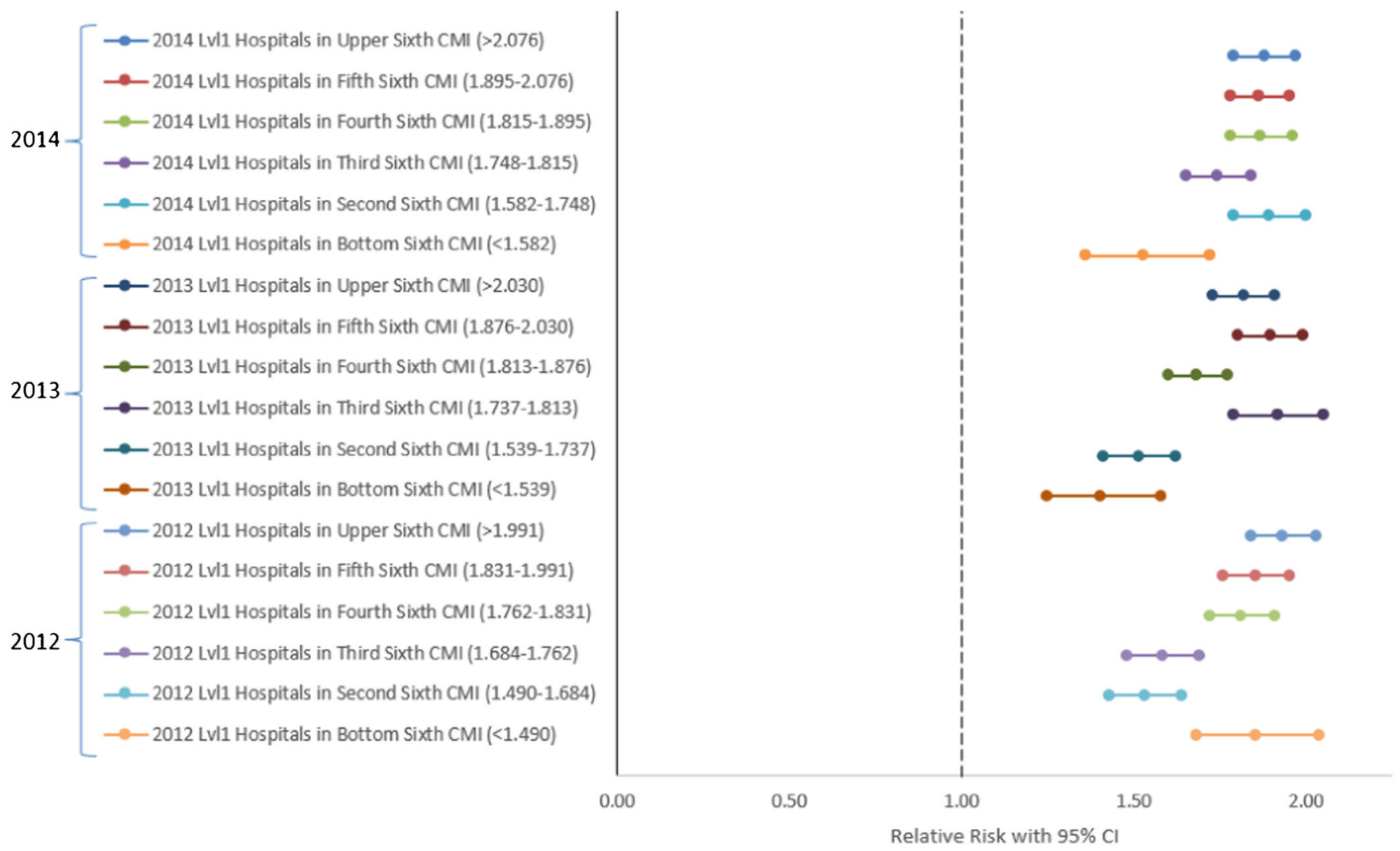

Figure 5 Relative risk of VTE in level I trauma hospitals by CMI grouping. 


\section{APPENDIX G}

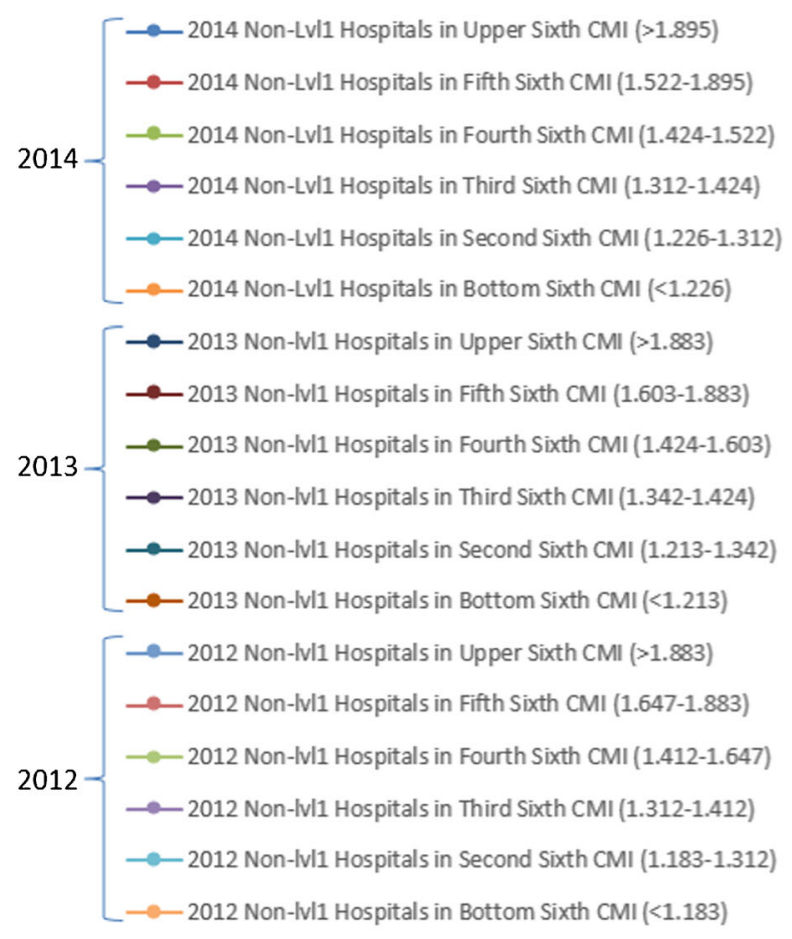

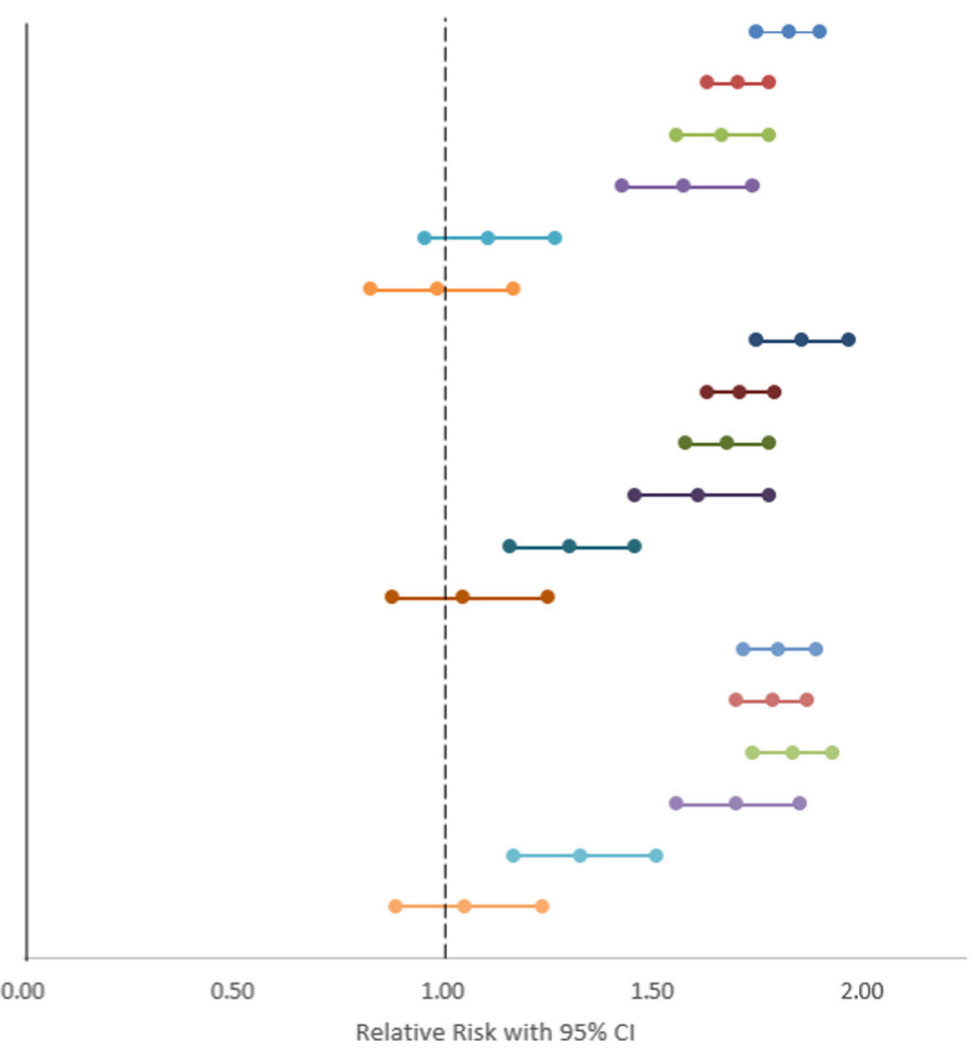

Figure 6 Relative risk of VTE in non-level I trauma hospitals by CMI grouping. 